\title{
Short-Term Effect of Autogenic Drainage on Ventilation Inhomogeneity in Adult Subjects With Stable Non-Cystic Fibrosis Bronchiectasis
}

\author{
William Poncin PT MSc, Grégory Reychler PT PhD, Noémie Leeuwerck PT, \\ Nathalie Bauwens PT, Anne-Sophie Aubriot PT MSc, Candice Nader PT, \\ Giuseppe Liistro MD PhD, and Sophie Gohy MD PhD
}

\begin{abstract}
BACKGROUND: Lung clearance index (LCI), a measure of ventilation inhomogeneity derived from a multiple-breath washout test, is a promising tool for assessing airway function in patients with non-cystic fibrosis bronchiectasis. However, it is unknown whether ventilation inhomogeneity could improve after successful elimination of excessive secretions within bronchiectasis. The objective of this work was to assess the short-term effects of lung secretion clearance using the autogenic drainage technique on standard lung function tests and LCI in subjects with non-cystic fibrosis bronchiectasis. METHODS: Nitrogen-based multiple-breath washout, spirometry, and body plethysmography tests were performed $30 \mathrm{~min}$ before autogenic drainage in adults with stable non-cystic fibrosis bronchiectasis. The autogenic drainage session was followed by a 5-min break, after which the tests were repeated in the same order. Sputum expectorated during autogenic drainage was quantified as dry weight and correlated with change between post- and pre-measurements $(\Delta)$. Paired $t$ test or Wilcoxon signed-rank tests were used to compare pre- and post-autogenic drainage measurement outcomes. A $P$ value of $\leq .05$ was considered as statistically significant. RESULTS: Twenty-four subjects were studied (18 females, median age [range]: 65 [21-81] y). Mean \pm SD LCI significantly improved after autogenic drainage $(10.88 \pm 2.62$ vs $10.53 \pm 2.35, P=.042)$. However, only $20 \%$ of subjects with mucus hyperproduction during autogenic drainage had a $\Delta$ LCI that exceeded measurement variability. The percent of predicted slow vital capacity (SVC\%) also slightly improved $(88.7 \pm 19.3 \%$ vs $90 \pm 19.1 \%, P=.02) . \Delta \mathrm{LCI}$ was inversely related to dry sputum weight $(\mathrm{r}=-.48, P=.02)$ and $\Delta \mathrm{SVC} \%(\mathrm{r}=-.64, P=.001) . \Delta \mathrm{SVC} \%$ also correlated with dry sputum weight $(r=0.46, P=.02)$. CONCLUSIONS: In adults with non-cystic fibrosis bronchiectasis and mucus hypersecretion, autogenic drainage improved ventilation inhomogeneity. LCI change may be the result of the maximum recruited lung volume and the amount of cleared mucus secretion. (ClinicalTrials.gov registration NCT02411981.) Key words: bronchiectasis; chest physiotherapy; airway clearance technique; autogenic drainage; lung clearance index; lung function tests. [Respir Care 2017;62(5):524-531. (C) 2017 Daedalus Enterprises]
\end{abstract}

\section{Introduction}

Non-cystic fibrosis bronchiectasis is a chronic lung disorder characterized by irreversible dilatation of the air-

Mr Poncin, Dr Reychler, Ms Leeuwerck, Ms Nader, Dr Liistro, and Dr Gohy are affiliated with the Department of Pneumology; Dr Reychler, Ms Bauwens, and Ms Aubriot are affiliated with Department of Physical Medicine and Rehabilitation; and Ms Bauwens, Ms Aubriot, and Dr Gohy are affiliated with the Cystic Fibrosis Unit, Cliniques Universita- ways. ${ }^{1}$ Clinical features include chronic cough, bronchorrhea, and recurrent exacerbations with concurrent impact on health-related quality of life, morbidity, and mortality rates. ${ }^{2-4}$ Among the current therapeutic arsenal offered to

ires Saint-Luc, Université Catholique de Louvain, Brussels, Belgium. Mr Poncin, Dr Reychler, Ms Aubriot, Dr Liistro, and Dr Gohy are affiliated with the Université Catholique de Louvain (UCL), Institute of Experimental and Clinical Research, Pole of Pneumology, ENT, and Dermatology, Brussels, Belgium. 
these patients, chest physiotherapy with bronchial drainage is acknowledged as an important element in their regular management. ${ }^{5}$ By facilitating discharge of excessive bronchial secretions, chest physiotherapy aims to maintain the patency of the airways to preserve lung function and

See the Related Editorial on Page 639

delay the progression of the disease. However, proving the effectiveness of treatments and especially chest physiotherapy via standard pulmonary function tests is challenging in patients with non-cystic fibrosis bronchiectasis. ${ }^{6-8}$ Indeed, current lung function end points, such as $\mathrm{FEV}_{1}$, lack the required sensitivity to allow early detection of treatment effects.9,10

In this context, the lung clearance index (LCI) derived from a multiple-breath washout test is of particular interest. LCI is a noninvasive and radiation-free measurement of ventilation inhomogeneity. Because sputum accumulation can contribute to the uneven distribution of ventilation, the elimination of airway secretions may promote its homogenization and therefore be captured by LCI measurement. In non-cystic fibrosis bronchiectasis, LCI has been shown to be repeatable and discriminatory and to be a more sensitive marker of lung function than $\mathrm{FEV}_{1},{ }^{11-13}$ but its role as a potential end point to demonstrate chest physiotherapy efficiency remains little explored. ${ }^{12}$

The primary aim of this study was to assess the impact of a 30-min-long autogenic drainage session on ventilation inhomogeneity via LCI in adults with stable non-cystic fibrosis bronchiectasis. We hypothesized that LCI change would inversely relate to the amount of expectorated sputum during the autogenic drainage session and/or with the severity of bronchiectasis, as measured with the recently developed bronchiectasis severity index. ${ }^{14}$

\section{Methods}

\section{Study Population}

Adults with stable non-cystic fibrosis bronchiectasis were prospectively recruited in the Cliniques Universitaires Saint-Luc (Brussels, Belgium) between March and October 2015. Participation was solicited via a telephone call or during a routine clinical consultation. Subjects were

The authors have disclosed no conflicts of interest.

Correspondence: William Poncin PT, MSc, Cliniques Universitaires Saint-Luc, Avenue Hippocrate 10, B-1200 Brussels, Belgium. E-mail: williamponcin8@gmail.com.

DOI: $10.4187 /$ respcare.05194

\section{QUICK LOOK}

\section{Current knowledge}

Chest physiotherapy is frequently advocated in patients with non-cystic fibrosis bronchiectasis to mobilize airway secretions, but assessing its impact using standard lung function end points is challenging. The lung clearance index is a noninvasive, sensitive, and convenient measurement of ventilation inhomogeneity. The effect of chest physiotherapy on ventilation inhomogeneity in patients with noncystic fibrosis bronchiectasis has been poorly described.

\section{What this paper contributes to our knowledge}

Chest physiotherapy improved ventilation inhomogeneity, and the magnitude of change of lung clearance index was related to the amount of secretion expectorated during the session. There was no difference in body plethysmography or spirometry measurements, except for slow vital capacity.

included if they were $\geq 18 \mathrm{y}$ old, had radiological evidence of bronchiectasis confirmed on high-resolution computed tomography, were clinically stable (no antibiotics in the preceding 4 weeks) and if the clinical notes within the year mentioned the presence of a chronic productive cough. Exclusion criteria included a diagnosis of cystic fibrosis, severe obstruction $\left(\mathrm{FEV}_{1}<30 \%\right.$ predicted), or inability to refrain from taking short-acting $\beta_{2}$ adrenoreceptor agonists, if prescribed, the day of the study. Written informed consent was obtained before inclusion. The study was approved by the local ethics committee (Comité d'Ethique Hospitalo-Facultaire Saint-Luc; institutional review board approval 00001530) and is registered in ClinicalTrials.gov (NCT02411981).

\section{Study Design}

Multiple-breath washout using nitrogen as inert gas, spirometry, and body plethysmography tests were performed 30 min before autogenic drainage. The autogenic drainage session was followed by a 5-min break, after which the tests were repeated in the same order. During both treatment and the resting period, subjects expectorated into a sterile transparent container. To account for salivary contamination, the secretions were dried in the container without the cap in an oven for at least $72 \mathrm{~h}$ at $70^{\circ} \mathrm{C}$. The masses of wet and dried secretions were thus measured.

\section{Measurements}

\section{Multiple-Breath Nitrogen Washout}

A commercially available open-circuit multiple-breath washout test with a hardware and software package was 
used for data processing and data analyses (Exhalyzer D and Spiroware 3.1, EcoMedics AG, Duernten, Switzerland). This setup measures nitrogen concentration indirectly from $\mathrm{O}_{2}$ (measured by a sidestream laser $\mathrm{O}_{2}$ sensor) and $\mathrm{CO}_{2}$ fraction (measured by mainstream infrared $\mathrm{CO}_{2}$ sensor). Flow and derived volumes were measured by a mainstream ultrasonic flow meter.

Subjects were examined in a sitting position, wearing a nose clip and breathing through a silicone mouthpiece. Multiple-breath washout tests were performed in accordance with the current consensus, ${ }^{15}$ albeit we performed 2 technically acceptable multiple-breath washout runs instead of 3 . We chose 2 runs because this significantly decreases testing time without influencing either mean LCI values or the test's sensitivity to detect abnormal ventilation distribution efficiency. ${ }^{16,17}$ Three or more runs were conducted whenever quality standards were not met. A run was considered complete when the nitrogen concentration fell below $2.5 \%(1 / 40)$ of its starting concentration for 3 consecutive end-tidal expirations. LCI was then calculated as the ratio of cumulative expired volume to functional residual capacity $\left(\mathrm{FRC}_{\text {washout }}\right)$, with cumulative expired volume defined as the sum of all expiratory volumes over the washout. $\mathrm{FRC}_{\text {washout }}$ was calculated as the ratio of exhaled nitrogen volume during the washout to the difference in starting and ending end-tidal fraction of that tracer gas. A multiple-breath washout run was discarded whenever leaks, sighs, or irregular breathing patterns occurred or if the FRC of one run differed by $>10 \%$ compared with the highest $\mathrm{FRC}_{\mathrm{washout}}$ of a valid measurement. Measurements were performed by a single operator certified by the European Cystic Fibrosis Society Clinical Trial Network standardization committee.

\section{Spirometry and Body Plethysmography}

Spirometry and body plethysmography (MasterScreen, Jaeger, Würzburg, Germany) were conducted according to American Thoracic Society/European Respiratory Society standards. ${ }^{18}$ Reported spirometry outcomes were slow vital capacity (SVC), FVC, $\mathrm{FEV}_{1}, \mathrm{FEV}_{1} / \mathrm{FVC}$, and forced expiratory flow at $25-75 \%$ of the FVC. Raw data were normalized (percent predicted and $\mathrm{Z}$ scores) according to the Global Lungs Initiative equations ${ }^{19}$ except for SVC, where the predictive equations of Pistelli et $\mathrm{al}^{20}$ were used. Body plethysmography measurements were $\mathrm{FRC}\left(\mathrm{FRC}_{\text {pleth }}\right)$, residual volume (RV), total lung capacity (TLC), RV/TLC, and specific airway resistance and conductance. Raw measurements were converted according to the predictive equations from Stocks and Quanjer. ${ }^{21}$

\section{Bronchiectasis Severity Index}

The bronchiectasis severity index is a recently validated multidimensional severity score for predicting future hos- pital admission and long-term mortality. ${ }^{14,22}$ The bronchiectasis severity index takes into account age, body mass index, $\mathrm{FEV}_{1}$, prior hospital admission and exacerbations, Medical Research Council dyspnea score, bacterial colonization, and high-resolution computed tomography score. The latter was carried out within a year of recruitment and scored by 2 independent operators. Otherwise, data were collected the day of the last routine medical visit.

\section{Chest Physiotherapy}

Autogenic drainage consists in maximizing expiratory air flow during tidal breathing at different lung volumes to mobilize the mucus while minimizing coughing episodes. ${ }^{23}$ Autogenic drainage is initiated at the expiratory reserve volume until the inspiratory reserve volume is reached. The treatment session progresses through 3 phases: (1) unsticking the secretions in low volume; (2) collecting at medium volume; and (3) evacuation by breathing at high volume. ${ }^{24}$ When sufficient mucus has reached the upper airways, the mucus can be expectorated by a cough or a huff. ${ }^{23,24}$ Autogenic drainage was performed in a semirecumbent position (at a $45^{\circ}$ angle from the horizontal).

\section{Statistical Analysis}

We estimated sample size based on the coefficient of repeatability of the LCI previously published. ${ }^{25}$ Using a 2 -sided $\alpha$ of .05 and assuming a mean LCI change of 1 unit and an SD difference of $1.8,{ }^{13}$ we estimated that recruiting 24 subjects would provide a power of .80 .

All analyses were performed using SPSS 22 (SPSS, Chicago, Illinois) software. Normality of data were verified with Kolmogorov-Smirnov and Shapiro-Wilk tests. For normally distributed data, values are presented as mean \pm SD. Non-normally distributed values and baseline characteristics are reported as median (interquartile range). Paired $t$ test or Wilcoxon signed-rank tests were used to compare pre- and post-chest physiotherapy measurement outcomes as appropriate. LCI and FRC are reported as the means of 2 technically acceptable multiple-breath washout runs within one test occasion. Within-test repeatability of LCI and FRC were calculated as the ratio of difference between runs over their average (\%). Changes in measurements with autogenic drainage were expressed as the difference between post- and pre-measurements $(\Delta)$. Using $\Delta \mathrm{LCI}$ of one lung turnover as a cutoff, participants were further divided into 2 groups, and the Mann-Whitney $U$ test was used to compare their variables. Relations between $\triangle \mathrm{LCI}$ and changes in other variables of interest or expectorated sputum weights were investigated by applying Pearson correlation coefficients. Bland-Altman statistics were carried out to assess the mean difference (bias) between $\mathrm{FRC}_{\text {pleth }}$ and $\mathrm{FRC}_{\text {washout }}$ in addition to the upper 


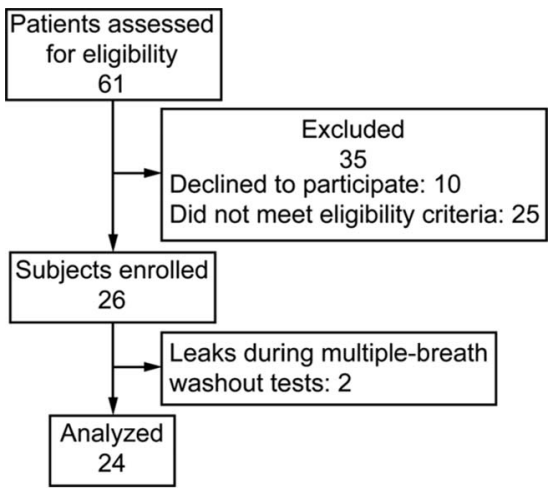

Fig. 1. Flow chart.

and lower $95 \%$ limits of agreement (bias $\pm 1.96 \mathrm{SD}$ of the difference). ${ }^{26}$ Finally, simple linear regression was conducted to model the relationships between FRC bias and lung function parameters. A $P$ value of $\leq .05$ was considered as statistically significant.

\section{Results}

\section{Study Population}

Twenty-six subjects were investigated. Two of them were excluded from any analysis because of repeated mouth leaks during consecutive multiple-breath washout runs, leaving 24 subjects (age 21-81 y) for the final analysis (Fig. 1). Baseline characteristics are displayed in Table 1. Pre- and post-autogenic drainage lung function measurements are presented in Table 2.

The medians (interquartile ranges) of wet and dry sputum weights were 12.75 (1.24-24.04) $\mathrm{g}$ and 0.44 (0.11.11) g, respectively. LCI and SVC (percent predicted) statistically improved after the chest physiotherapy session (Table 2). No other lung function outcome differed statistically. $\Delta$ LCI was inversely correlated with spirometry measurement change and expectorated sputum weights (Fig. 2). $\triangle \mathrm{SVC}$ (percent predicted) was also correlated with wet sputum weight $(\mathrm{r}=.52, P=.01)$ and dry sputum weight $(\mathrm{r}=.46, P=.02)$. The bronchiectasis severity index total score and its categories were not related to any lung function measurements at baseline nor to their respective change with autogenic drainage. Using an LCI difference of 1 unit as a meaningful cutoff, ${ }^{25}$ only 5 subjects $(21 \%)$ had a relevant change (all improved). The bronchiectasis etiologies among those subjects were: primary ciliary dyskinesia (3), idiopathic (1), and post-infectious (1). The amount of cleared sputum and the associated gain of SVC were significantly more important in these 5 responders compared with the other participants: medians (interquartile ranges) of wet sputum weight, 24.7 (21.4-37.4) g versus $9.6(0.9-21.9) \mathrm{g}$; dry sputum weight, $1.3(0.9-2.3) \mathrm{g}$ ver-
Table 1. Baseline Characteristics of the Study Population

\begin{tabular}{|c|c|}
\hline Characteristics $(N=24)$ & Values \\
\hline Female/male sex, $n$ & $16 / 8$ \\
\hline Age, median (IQR) y & $65(36-71)$ \\
\hline \multicolumn{2}{|l|}{ Etiology, $n(\%)$} \\
\hline Idiopathic & $12(50)$ \\
\hline Post-infective & $5(21)$ \\
\hline Primary ciliary dyskinesia & $5(21)$ \\
\hline Immune deficiency & $1(4)$ \\
\hline Severe gastro-esophageal reflux & $1(4)$ \\
\hline \multicolumn{2}{|l|}{ BSI, $n(\%)$} \\
\hline Mild, 0-4 & $11(46)$ \\
\hline Moderate, 5-8 & $6(25)$ \\
\hline Severe, $\geq 9$ & $7(28)$ \\
\hline $\mathrm{FEV}_{1}$, median (IQR) $\%$ predicted & $87.3(66.6-97.3)$ \\
\hline $\mathrm{FEV}_{1}$, median (IQR), Z-score & $-0.87(-2.36$ to -0.22$)$ \\
\hline $\mathrm{FEV}_{1} / \mathrm{FVC}$, median (IQR) & $0.72(0.64-0.77)$ \\
\hline $\mathrm{FEV}_{1} / \mathrm{FVC}$, median (IQR), Z-score & $-0.99(-2.1$ to -0.41$)$ \\
\hline $\mathrm{FEF}_{25-75 \%}$, median (IQR) $\%$ predicted & $60.6(39-90.4)$ \\
\hline $\mathrm{FEF}_{25-75 \%}$, median (IQR), Z-score & $-1.31(-2.12$ to -0.25$)$ \\
\hline LCI, median (IQR), turnover & $10.28(8.71-12.99)$ \\
\hline \multicolumn{2}{|c|}{$\begin{array}{l}\mathrm{IQR}=\text { interquartile range } \\
\mathrm{BSI}=\text { bronchiectasis severity index } \\
\mathrm{FEF}_{25-75 \%}=\text { forced expiratory flow between } 25 \text { and } 75 \% \text { of FVC } \\
\mathrm{LCI}=\text { lung clearance index }\end{array}$} \\
\hline
\end{tabular}

sus $0.2(0.1-0.7) \mathrm{g}$; SVC (percent predicted), 5.3 (1.1$5.9) \%$ versus 0.6 ( -0.4 to 1.4$) \% ; P \leq .01$.

Before autogenic drainage, there was a small but significant bias toward higher $\mathrm{FRC}_{\text {pleth }}$ when compared with $\mathrm{FRC}_{\text {washout }}$, suggesting trapped gas within the lungs. Mean difference $(95 \% \mathrm{CI})$ was $0.19 \mathrm{~L}(0.05-0.34 \mathrm{~L}), P=.01$. Limits of agreement were -0.47 and $0.86 \mathrm{~L}$; the corresponding relative mean difference was $7.6 \%$, and limits of agreement were -14.5 to $29.6 \%$. Linear regression shows that normalized RV/TLC and RV explained $21 \%\left(\mathrm{R}^{2}=.21\right)$ and $18 \%\left(\mathrm{R}^{2}=.18\right)$ of the variability of trapped gas $\left(\mathrm{FRC}_{\text {pleth }}-\mathrm{FRC}_{\text {washout }}\right)$ before autogenic drainage, respectively. Similar results were observed after autogenic drainage (data not shown).

\section{Discussion}

In this study, we show that LCI significantly improved after an airway clearance session. However, only 5 of 24 subjects showed an improvement in ventilation inhomogeneity that exceeded measurement variability. The magnitude of LCI change was independent of disease severity but was rather related to the change of SVC and the amount of cleared sputum. Taken together, our findings suggest that the recruitment of lung volumes following elimination of excessive airway secretions results in a redistribution of ventilation, improving gas mixing efficiency. According 
Table 2. Lung Function Measurement Outcomes Before and After Chest Physiotherapy

\begin{tabular}{|c|c|c|c|}
\hline Outcomes & Pre-AD & Post-AD & $P$ \\
\hline \multicolumn{4}{|l|}{ Multiple-breath washout } \\
\hline LCI, mean $\pm \mathrm{SD}$ turnover & $10.88 \pm 0.54$ & $10.53 \pm 0.48$ & .042 \\
\hline LCI repeatability, $\%$ & 4.2 & 2.9 & \\
\hline $\mathrm{FRC}_{\text {washout }}$, mean $\pm \mathrm{SD} \mathrm{L}$ & $3.06 \pm 0.99$ & $3.07 \pm 1.0$ & .91 \\
\hline FRC repeatability, \% & 5 & 4.7 & \\
\hline \multicolumn{4}{|l|}{ Spirometry } \\
\hline SVC, mean $\pm \mathrm{SD} \%$ predicted & $88.7 \pm 19.3$ & $90.0 \pm 19.1$ & .02 \\
\hline $\mathrm{FEV}_{1}$, median (IQR) $\%$ predicted & $87.3(66.3-97.6)$ & $87(67.2-100.6)$ & .69 \\
\hline $\mathrm{FVC}$, mean $\pm \mathrm{SD} \%$ predicted & $94.4 \pm 21.6$ & $95.3 \pm 21.5$ & .19 \\
\hline $\mathrm{FEV}_{1} / \mathrm{FVC}$, mean $\pm \mathrm{SD}$ & $0.71 \pm 0.10$ & $0.70 \pm 0.10$ & .08 \\
\hline $\mathrm{FEF}_{25-75 \%}$, median (IQR) \% predicted & $60.6(37.2-90.6)$ & $59.2(37.6-90.8)$ & .09 \\
\hline \multicolumn{4}{|l|}{ Body plethysmography } \\
\hline $\mathrm{FRC}_{\text {pleth }}$, median (IQR) \% predicted & $107(102.5-128)$ & $109(99-128.5)$ & .83 \\
\hline $\mathrm{RV}$, mean $\pm \mathrm{SD} \%$ predicted & $121.67 \pm 21.35$ & $123.42 \pm 23.33$ & .49 \\
\hline TLC, median (IQR) \% predicted & $105.5(95.5-111)$ & $108(97.5-113.5)$ & .13 \\
\hline RV/TLC, median (IQR) \% predicted & $106.5(96.8-125.5)$ & $109(101-127.8)$ & .86 \\
\hline Specific $\mathrm{R}_{\mathrm{aw}}$, mean $\pm \mathrm{SD}$ mmHg $\cdot \mathrm{s}$ & $10.81 \pm 4.31$ & $10.04 \pm 4.41$ & .22 \\
\hline Specific $\mathrm{G}_{\mathrm{aw}}$, mean $\pm \mathrm{SD} 1 / \mathrm{mmHg} \cdot \mathrm{s}$ & $0.12 \pm 0.05$ & $0.12 \pm 0.05$ & .18 \\
\hline $\begin{array}{l}\mathrm{AD}=\text { autogenic drainage } \\
\mathrm{LCI}=\text { lung clearance index } \\
\mathrm{FRC}=\text { functional residual capacity } \\
\mathrm{SVC}=\text { slow vital capacity } \\
\mathrm{IQR}=\text { interquartile range } \\
\mathrm{FEF} \mathrm{F}_{25-75 \%}=\text { forced expiratory flow between } 25 \text { and } 7 \\
\text { pleth }=\text { body plethysmography } \\
\mathrm{RV}=\text { residual volume } \\
\mathrm{TLC}=\text { total lung capacity } \\
\mathrm{R}_{\mathrm{aw}}=\text { airway resistance } \\
\mathrm{G}_{\mathrm{aw}}=\text { airway conductance }\end{array}$ & & & \\
\hline
\end{tabular}

to our data, we believe that the quantity of mobilized sputum with treatment should be taken into consideration when assessing the effects of chest physiotherapy on ventilation inhomogeneity.

Our results contrast with previous studies investigating the role of physiotherapy on ventilation inhomogeneity through LCI. Although physiotherapy modalities and the allocated time for airway clearance technique duration differed between studies, their analyses systematically concluded that there was no consistent effect on lung ventilation maldistribution. ${ }^{12,27,28}$ However, the mean LCI improvement in our study was rather weak, with a mean relative decrease of $3 \%$, well below the $10 \%$ corresponding to the magnitude of between-test variability. ${ }^{25}$ Looking for individual physiologically meaningful change (ie, $\Delta$ LCI $\geq 1$ lung turnover), ${ }^{25}$ only 5 subjects $(21 \%)$ improved. Interestingly, although Pfleger et $\mathrm{al}^{28}$ did not find mean LCI change after a 30 -min-long supervised positive expiratory pressure mask therapy session in cystic fibrosis, 17 of 29 subjects (59\%) had a physiologically relevant LCI change (10 had an LCI increase $\geq 1$ lung turnover, whereas 7 decreased). The paradoxical rise of LCI after chest physiotherapy is an acknowledged phenomenon attributed to the unveiling of newly partially obstructed airways previ- ously completely plugged and therefore not contributing earlier to ventilation inhomogeneity. ${ }^{15}$ In other words, individual relevant alterations in gas mixing were greater in their study. We assume that the underlying pathophysiological condition may partly explain these discrepancies. In cystic fibrosis, the lungs are diffusely and unevenly affected, with chronic sputum hyperproduction being a common clinical sign. ${ }^{29-31}$ Likewise, non-cystic fibrosis bronchiectasis is a lung disease involving patchy defects, but etiologies are various, and the airways can be either diffusely or locally affected. ${ }^{1}$ In the latter forms, the net effect of airway clearance therapy might not be sufficient to provoke demonstrable LCI change. Our responders cleared a greater amount of sputum during the autogenic drainage session in comparison with the remainder of the subject cohort. In addition, 3 of the 5 responders had primary ciliary dyskinesia, a disease that shares common features with cystic fibrosis. This suggests that a minimum amount of sputum needs to be mobilized to elicit a detectable effect on ventilation inhomogeneity.

Recently, Lin et $\mathrm{al}^{32}$ have shown that the direction and magnitude of LCI change varied over time after a chest physiotherapy session in children with an exacerbation of cystic fibrosis. LCI worsened and peaked at $1 \mathrm{~h}$ post-chest 

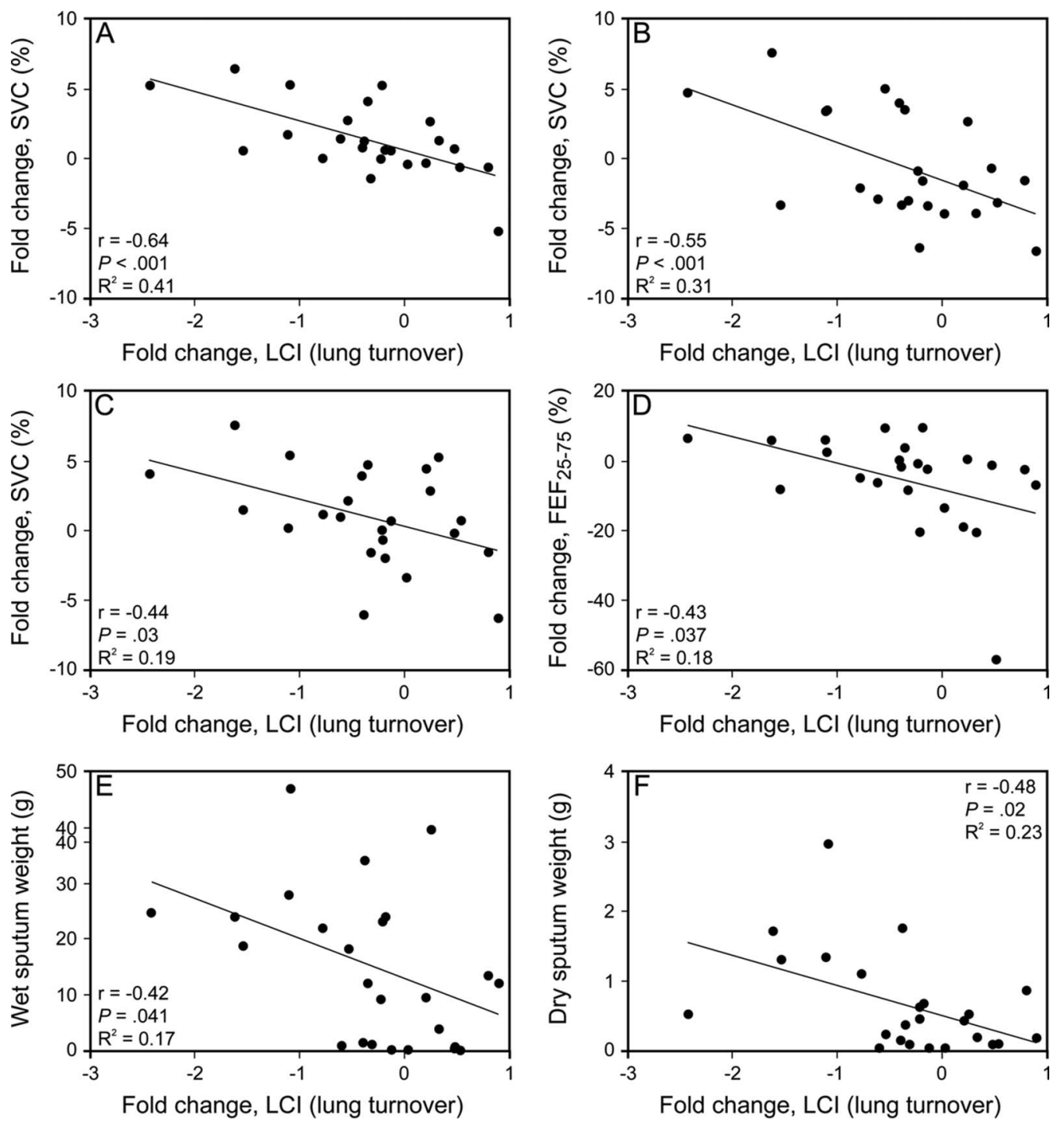

Fig. 2. Relation between lung clearance index (LCl) difference and pulmonary lung function measurement changes or sputum weights, reported as Pearson $r$ and linear regression $\left(R^{2}\right)$. Shown is the correlation between $L C l$ difference and change in percent predicted slow vital capacity (SVC) (A), change in percent predicted $\mathrm{FEV}_{1}(\mathrm{~B})$, change in percent predicted FVC (C), change in percent predicted forced expiratory flow between 25 and $75 \%$ of $F V C\left(\mathrm{FEF}_{25-75 \%}\right)(\mathrm{D})$, change in wet sputum weight $(\mathrm{E})$, and change in dry sputum weight $(\mathrm{F})$. Linear regression lines are shown.

physiotherapy and then slowly decreased to finally become significantly lower than the baseline value $24 \mathrm{~h}$ after chest physiotherapy. On the other hand, the time-course chest physiotherapy effect on $\mathrm{FEV}_{1}$ in subjects with cystic fibrosis displayed a different pattern of change, with an optimal improvement observed between $30 \mathrm{~min}$ and $2 \mathrm{~h}$ after the physiotherapy session. ${ }^{33}$ In our study, lung function tests were performed nearly immediately after the chest physiotherapy session, whereas Pfleger et $\mathrm{al}^{28}$ and Grillo et al ${ }^{12}$ performed tests 30 and 60 min after the chest physiotherapy session, respectively. Both studies observed a clinically small but significant improvement in $\mathrm{FEV}_{1}$ with no mean LCI change, the opposite of what we found.
Measurement time points are therefore an additional potential issue to consider when assessing chest physiotherapy effectiveness, and future studies attempting to clarify underpinning mechanisms are necessary.

We also observed a significant bias toward lower $\mathrm{FRC}_{\text {washout }}$ values as compared with $\mathrm{FRC}_{\text {pleth }}$. Body plethysmography uses Boyle's law to determine lung volumes and takes into account all compressible gases within the thorax, whereas inert nitrogen washout uses dilution properties of gases, only considering those in communication with the mouth. The difference between both measurements is therefore expected in obstructive diseases and provides an estimate of gas trapped in the lungs. ${ }^{34}$ How- 


\section{Autogenic Drainage in Non-CF Bronchiectasis}

ever, it is also admitted that the commercial multiplebreath nitrogen washout device used in this study overestimates true FRC to such an extent that some authors even report higher $\mathrm{FRC}_{\text {washout }}$ than $\mathrm{FRC}_{\text {pleth }} \cdot{ }^{35-38}$ The mechanism behind this remains unclear, but because we found a small positive bias toward higher $\mathrm{FRC}_{\text {pleth }}$, we assume that substantial volumes of gas were trapped in a number of our subjects. The relatively high values observed in RV and RV/TLC, both markers also traditionally utilized to represent gas trapping, ${ }^{34,39}$ and their positive associations with the magnitude of the bias (ie, $\mathrm{FRC}_{\text {pleth }}-\mathrm{FRC}_{\text {washout }}$ ) further support this hypothesis.

Limitations of this research include the heterogeneity of the disease and the inherent wide spectrum of excessive mucus production between subjects. Another limitation was the measure of expectorated sputum weight itself. Indeed, sputum can be unintentionally swallowed, therefore inducing error in the calculations. Finally, because the intervention was not controlled, it was also not possible to conclude that the result was the effect of autogenic drainage alone. Forced expiratory maneuvers associated with spirometry measurements or coughing and huffing episodes interspersing with the autogenic drainage technique could also account for ventilation redistribution.

\section{Conclusions}

We found a small but statistically significant short-term impact on uniformity of gas distribution following an autogenic drainage session in subjects with non-cystic fibrosis bronchiectasis. However, only a small subgroup of subjects with mucus hypersecretion showed an improvement in ventilation inhomogeneity that exceeded measurement variability. It suggests that mucus hyperproduction could be a prerequisite to provoke a physiologically meaningful change in ventilation inhomogeneity with airway clearance techniques.

\section{ACKNOWLEDGMENTS}

We thank Prof. Thierry Pieters, Constant Pahulycz, Prof. Teresinha Leal, Dr Sabrina Noel, Barbara Dhooghe, and all of the lung function test technicians from the Department of Pneumology for kind assistance during the completion of this study. We are also grateful to Michelle Thomas, David Gibas, and especially Krista Revert for meaningful comments regarding the manuscript. We also thank all of the subjects who participated in the study.

\section{REFERENCES}

1. Barker AF. Bronchiectasis. N Engl J Med 2002;346(18):1383-1393.

2. McDonnell MJ, Ward C, Lordan JL, Rutherford RM. Non-cystic fibrosis bronchiectasis. QJM 2013;106(8):709-715.

3. Loebinger MR, Wells AU, Hansell DM, Chinyanganya N, Devaraj A, Meister M, Wilson R. Mortality in bronchiectasis: a long-term study assessing the factors influencing survival. Eur Respir J 2009; 34(4):843-849.
4. McShane PJ, Naureckas ET, Tino G, Strek ME. Non-cystic fibrosis bronchiectasis. Am J Respir Crit Care Med 2013;188(6):647-656.

5. Pasteur MC, Bilton D, Hill AT. British Thoracic Society guideline for non-CF bronchiectasis. Thorax 2010;65(Suppl 1):i1-58.

6. Lee AL, Burge AT, Holland AE. Airway clearance techniques for bronchiectasis. Cochrane Database Syst Rev 2015;(11):CD008351.

7. Herrero-Cortina B, Vilaró J, Martí D, Torres A, San Miguel-Pagola M, Alcaraz V, Polverino E. Short-term effects of three slow expiratory airway clearance techniques in patients with bronchiectasis: a randomised crossover trial. Physiotherapy 2016;102(4):357-364.

8. Snijders D, Fernandez Dominguez B, Calgaro S, Bertozzi I, Escribano Montaner A, Perilongo G, Barbato A. Mucociliary clearance techniques for treating non-cystic fibrosis bronchiectasis: is there evidence? Int J Immunopathol Pharmacol 2015;28(2):150-159.

9. Smith MP, Hill AT. Evaluating success of therapy for bronchiectasis: what end points to use? Clin Chest Med 2012;33(2):329-349.

10. Stanojevic S, Ratjen F. Physiologic endpoints for clinical studies for cystic fibrosis. J Cyst Fibros 2016;15(4):416-423.

11. Gonem S, Scadding A, Soares M, Singapuri A, Gustafsson P, Ohri $\mathrm{C}$, et al. Lung clearance index in adults with non-cystic fibrosis bronchiectasis. Respir Res 2014;15:59.

12. Grillo L, Irving S, Hansell DM, Nair A, Annan B, Ward S, et al. The reproducibility and responsiveness of the lung clearance index in bronchiectasis. Eur Respir J 2015;46(6):1645-1653.

13. Rowan SA, Bradley JM, Bradbury I, Lawson J, Lynch T, Gustafsson $\mathrm{P}$, et al. Lung clearance index is a repeatable and sensitive indicator of radiological changes in bronchiectasis. Am J Respir Crit Care Med 2014;189(5):586-592.

14. Chalmers JD, Goeminne P, Aliberti S, McDonnell MJ, Lonni S, Davidson J, et al. The bronchiectasis severity index: an international derivation and validation study. Am J Respir Crit Care Med 2014; 189(5):576-585.

15. Robinson PD, Latzin P, Verbanck S, Hall GL, Horsley A, Gappa M, et al. Consensus statement for inert gas washout measurement using multiple- and single- breath tests. Eur Respir J 2013;41(3):507-522.

16. Robinson PD, Stocks J, Aurora P, Lum S. Abbreviated multi-breath washout for calculation of lung clearance index. Pediatr Pulmonol 2013;48(4):336-343.

17. Yammine S, Singer F, Abbas C, Roos M, Latzin P. Multiple-breath washout measurements can be significantly shortened in children. Thorax 2013;68(6):586-587.

18. Miller MR, Hankinson J, Brusasco V, Burgos F, Casaburi R, Coates A, et al. Standardisation of spirometry. Eur Respir J 2005;26(2):319338.

19. Quanjer PH, Stanojevic S, Cole TJ, Baur X, Hall GL, Culver BH, et al. Multi-ethnic reference values for spirometry for the 3-95-yr age range: the global lung function 2012 equations. Eur Respir J 2012; 40(6):1324-1343.

20. Pistelli F, Bottai M, Viegi G, Di Pede F, Carrozzi L, Baldacci S, et al. Smooth reference equations for slow vital capacity and flowvolume curve indexes. Am J Respir Crit Care Med 2000;161(3 Pt 1):899-905

21. Stocks J, Quanjer PH. Reference values for residual volume, functional residual capacity and total lung capacity. Eur Respir J 1995; 8(3):492-506

22. Guan WJ, Chen RC, Zhong NS. The bronchiectasis severity index and FACED score for bronchiectasis. Eur Respir J 2016;47(2):382384.

23. Pryor JA. Physiotherapy for airway clearance in adults. Eur Respir J 1999;14(6): 1418-1424.

24. Agostini P, Knowles N. Autogenic drainage: the technique, physiological basis and evidence. Physiotherapy 2007;93(2):157-163.

25. Singer F, Kieninger E, Abbas C, Yammine S, Fuchs O, Proietti E, et al. Practicability of nitrogen multiple-breath washout measure- 


\section{Autogenic Drainage in Non-CF Bronchiectasis}

ments in a pediatric cystic fibrosis outpatient setting. Pediatr Pulmonol 2013;48(8):739-746.

26. Bland JM, Altman DG. Statistical methods for assessing agreement between two methods of clinical measurement. Lancet 1986;1(8476): 307-310.

27. Fuchs SI, Toussaint S, Edlhaimb B, Ballmann M, Gappa M. Shortterm effect of physiotherapy on variability of the lung clearance index in children with cystic fibrosis. Pediatr Pulmonol 2010;45(3): 301-306.

28. Pfleger A, Steinbacher M, Schwantzer G, Weinhandl E, Wagner M, Eber E. Short-term effects of physiotherapy on ventilation inhomogeneity in cystic fibrosis patients with a wide range of lung disease severity. J Cyst Fibros 2015;14(5):627-631.

29. Ratjen F, Döring G. Cystic fibrosis. Lancet 2003;361(9358):681-689.

30. Bannier E, Cieslar K, Mosbah K, Aubert F, Duboeuf F, Salhi Z, et al. Hyperpolarized $3 \mathrm{He}$ MR for sensitive imaging of ventilation function and treatment efficiency in young cystic fibrosis patients with normal lung function. Radiology 2010;255(1):225-232.

31. Sun Y, O'Sullivan BP, Roche JP, Walvick R, Reno A, Baker D, et al. Using hyperpolarized 3He MRI to evaluate treatment efficacy in cystic fibrosis patients. J Magn Reson Imaging 2011;34(5):12061211.

32. Lin B, Yabsley P, Middleton A, Robinson P, Jaffe A, Selvadurai H. Acute changes in the lung clearance index after physiotherapy in children with cystic fibrosis. J Cyst Fibros 2015;14(Suppl 1):S39.
33. Rodriguez Hortal MC, Hjelte L. Time point to perform lung function tests evaluating the effects of an airway clearance therapy session in cystic fibrosis. Respir Care 2014;59(10):1537-1541.

34. Ruppel GL. What is the clinical value of lung volumes? Respir Care 2012;57(1):26-35; discussion 35-38

35. Clermons K, Cornelussen S, Martin L, Bongaerts P, Van der Grinten C. Selecting a multiple-breath N2 washout device: the search continues. Eur Respir J 2015;46(suppl):59.

36. Raaijmakers L, Jensen R, Stanojevic S, Merkus P, Ratjen F. In vitro and in vivo comparison of two multiple breath nitrogen washout devices. Eur Respir J 2015;46(suppl):59.

37. Raywood E, Duncan J, Wade A, Stocks J, Bush A, Aurora P. Validation of commercial devices for measurement of lung clearance index (LCI) and functional residual capacity (FRC) in school-aged children. Eur Respir J 2015;46(suppl):59.

38. Zuo L, Pannell BK, Horsley A, Bell N, Kane M, Ratjen F, et al. Commentaries on viewpoint: using the same cut-off for sulfur hexafluoride and nitrogen multiple-breath washout may not be appropriate. J Appl Physiol 2015;119(12):1513-1514.

39. Smith BM, Hoffman EA, Basner RC, Kawut SM, Kalhan R, Barr RG. Not all measures of hyperinflation are created equal: lung structure and clinical correlates of gas trapping and hyperexpansion in COPD: the multi-ethnic study of atherosclerosis (MESA) COPD study. Chest 2014;145(6):1305-1315.

This article is approved for Continuing Respiratory Care Education credit. For information and to obtain your CRCE

(free to AARC members) visit www.rcjournal.com

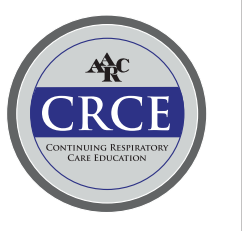

